\title{
Determination of stress-strain state of the wooden church log walls with software package
}

\author{
Anastasia Chulkova ${ }^{1}$, Sergey Lukichev ${ }^{1,{ }^{*}}$, Marina Romanovich $^{1}$ \\ ${ }^{1}$ Peter the Great Saint-Petersburg Polytechnic University, 195251 St. Petersburg, Russia
}

\begin{abstract}
The restoration of architectural monuments is going on all over the world today. The main aim of restoration is the renewal of stable functioning of building constructions in normal state. In this article, we have tried to figure out with special software the bearing capacity of log cabins of the Church of Transfiguration on Kizhi island. As shown in research results, determination of stress-strain stage with software package is necessary for the bearing capacity computation as well as field tests.
\end{abstract}

\section{Introduction}

Kizhi is an island nearby the lake Onega. It is one of the greatest open-air museums in Russian Federation since 1960. Kizhi is a unique historical and cultural complex, which is considered to be a particularly valuable object of Russian cultural heritage. The architectural ensemble "Kizhi Pogost" belongs to UNESCO World Heritage site. The central object of the museum is the Church of Transfiguration, which was built in 1714 . This building is unique because there are no nails in the whole construction [1].

The purpose of the study is research of the Church of Transfiguration wooden constructions, which are over the age of 300 years. The study was also expected to reason a need of construction reinforcement and to give some information for working up of the optimal reinforcement project. It is essential to build up a design model, which would work excellently, for using it while designing the reinforcement project of restoration.

Following theoretical and design problems are solving in the process:

- $\quad$ studying of the log cabins imperfections influence on a bearing capacity;

- studying of bearing zones and contact zones of logs and its intermediate elements;

- $\quad$ optimisation of diametres and spacing of the intermediate elements.

\section{Material and methods}

The constructive basis of the church is a pyramid. The basis of constructive volume of the church - a pyramidal shape. There are several design types in the building that are connected to each other shaping a unified form. A basement of the church is made of separate boulders. The bearing constructions above the basement are walls made of

* Corresponding author: serj_lu@mail.ru 
horizontal $\operatorname{logs}-\log$ cabins. These are vertical panels, which thickness is determined by diameters of the logs $(20-30 \mathrm{~cm})$. The panels are arranged to a plan, that consists of rectangles and octagons. The main octagon is connected to the basement by four walls. This octagon supports upper constructions, such as smaller octagons and rectangles and 22 domes. There are rectangles of log panels in each octagon for bearing upper smaller octagon [2-3].

Quadrangle are square in terms of intersecting walls. Each wall is made of several beams arranged in the same vertical plane one above the other with a gap, which is determined by the diameter of the log of the orthogonal faces. Logs quadrangle walls in areas of mutual intersection has no cuttings and freely reach the poles (diagonal walls), creating girder design. Collaboration logs in the quadrangle provides pads in the gaps. The building is middle and upper quadrangular create a support for the middle and upper octagons. This is the most crucial elements of the building, since they represent a large span structure made of conventional logs. This transferred the load of its own weight upstream structures are also snow and wind loads, the intensity of which increases with height in the middle and the upper quadrangle.

All of the above various types of design are combined in a single volume, the calculated scheme is very difficult to interpret. These circumstances, together with the natural imperfections of the wood, have a negative impact on the reliability of settlement schemes and require a cautious approach to the results of calculations [4-7].

The most problematic part of the church is the average bushel with the side faces approximately $9.6 \mathrm{~m}$ due to its design features and a large number of perceived stress. Deflections of beams medium quadrangular reach $14 \mathrm{~cm}$ (1/17 of flight), which exceeds the allowable.

The basic design scheme chosen the northern wall of the middle of the quadrangle. The following conditional premises were adopted:

Panel 5 consists of a timber with a length of $9.6 \mathrm{~m}$, diameter $30 \mathrm{~cm}$ originally adopted;

load acting only in the vertical direction;

in spans load beams must pass each other through the spacers, which is now lost. The gaskets are included in the calculation scheme, adopted by their step $2 \mathrm{~m}$ from the mean;

laying modeled vertical links with stiffness corresponding to the logs;

The natural curvature of the timber is taken into account the position deviation of the average units of the vertical plane.

Loads timbered panel have been adopted according to LLC "Stroyrekonstruktsiya". It is uniformly distributed load from the overlying structures $\mathrm{q}=5.3 \mathrm{~T} / \mathrm{m}$, attributable to the middle part of the top of the log. Also according to LLC "Stroyrekonstruktsiya" accepted deviations from the middle of the logs to the longitudinal axis (natural bending); to the north wall is: 


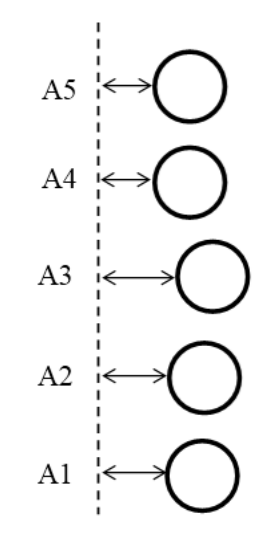

Fig. 1. Deviations logs.

Table 1. Setting Word's margins.

\begin{tabular}{|c|c|}
\hline Marking & Value \\
\hline $\mathrm{A} 5$ & - \\
\hline $\mathrm{A} 4$ & 0 \\
\hline $\mathrm{A} 3$ & -15.5 \\
\hline $\mathrm{A} 2$ & -9 \\
\hline $\mathrm{A} 1$ & -8 \\
\hline
\end{tabular}

For modeling of design scheme FEM tools were used. Design scheme was simulated as a truss model in the Lira SAPR software. Stiffness for truss elements were modelled by means of numerical descriptions: $E F$ is a longitudinal stiffness, where $F=\pi D^{2} / 4$ is the area of element; $E I_{z}=E I_{y}$ is a bending stiffness, where $I_{z}=I_{y}=\pi D^{4} / 64$ are the moments of inertia. All these characteristics for logs and intermediate elements were calculated and provided in Table 1. Stiffness pads is taken to be the stiffness of logs, because they fill the distance between the logs equal to their diameter [8-11].

Table 2. Setting Word's margins.

\begin{tabular}{|c|c|}
\hline Argument & Value \\
\hline$E F,[T]$ & 70650 \\
\hline$E I_{z}=E I_{y}$, & 397.4 \\
{$\left[T \cdot m^{2}\right]$} & \\
\hline
\end{tabular}

\section{Results and Discussion}

The log ending junctions were taken into consideration by putting braces in ending joints of truss elements. There are prohibitions of straight displacements by the main axes $(\mathrm{X}, \mathrm{Y}, \mathrm{Z})$ and rotation displacements by the $\mathrm{X}$ (longitudinal) axis on the one ending, and prohibition of straight displacement by $\mathrm{Y}$ and $\mathrm{Z}$ (vertical displacement) axis on the other ending. It was made for correct calculation and output data. The other joints are not fixed in space, but are stiff and provide rigid connections between longitude truss elements. 
In contact zones of logs and its intermediate elements there are hinged ends. A hinge means the removal or restriction of bend stiffness of a truss bar ending and a joint of elements. A hinge may be set on the one ending of an element or on both by some degree of freedom. It is allowed to set angled (around the main axes) or linear hinges (along the axes). Appropriate stiffness should be set to hinges. If stiffness of a hinge is zero, it is called the straight hinge. If stiffness is set by a huge number, than a rigid bending between an element and a scheme joint. By varying these parameters correct design model working is attained. It should match the real construction behavior [12-15].

The most realistic functioning of the design scheme was achieved with following parameters of hinges: $\mathrm{X} 1, \mathrm{Y} 1, \mathrm{Z} 1=0$ (for displacements along the axes), Ux, Uy, Uz $=1000 \mathrm{ton} \cdot \mathrm{m}$ (for displacements around the axes) on both endings of an intermediate element.

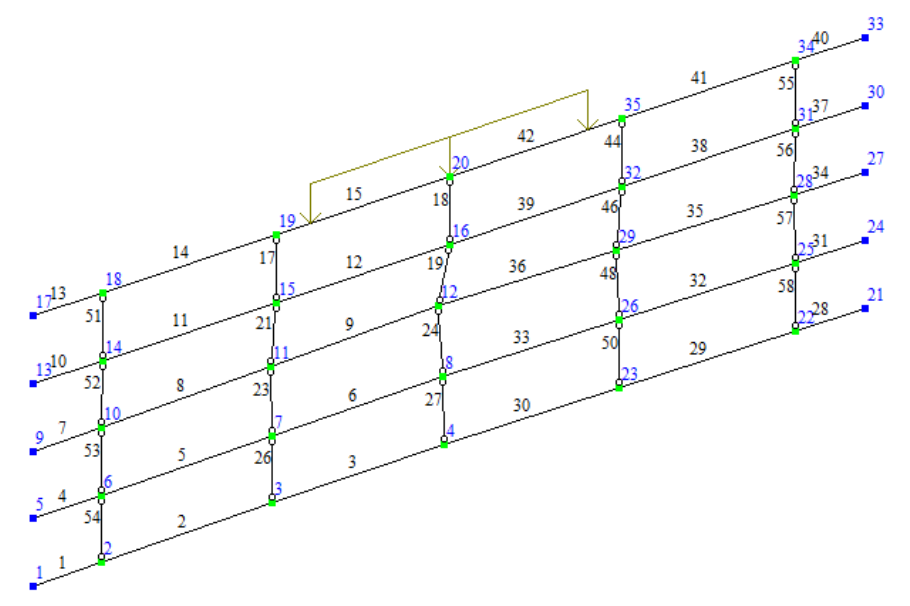

Fig. 2. The design scheme of a log wall.

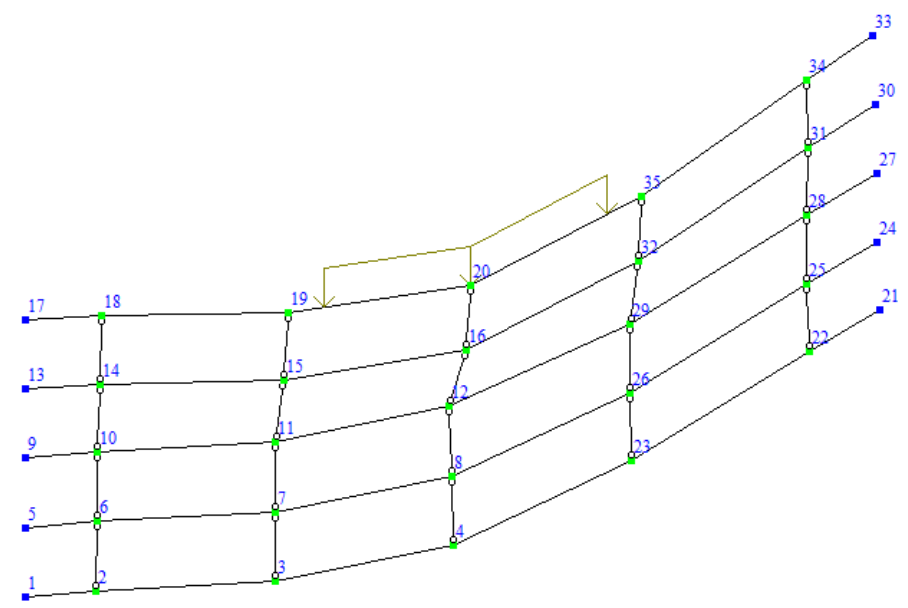

Fig. 3. The strain state. 


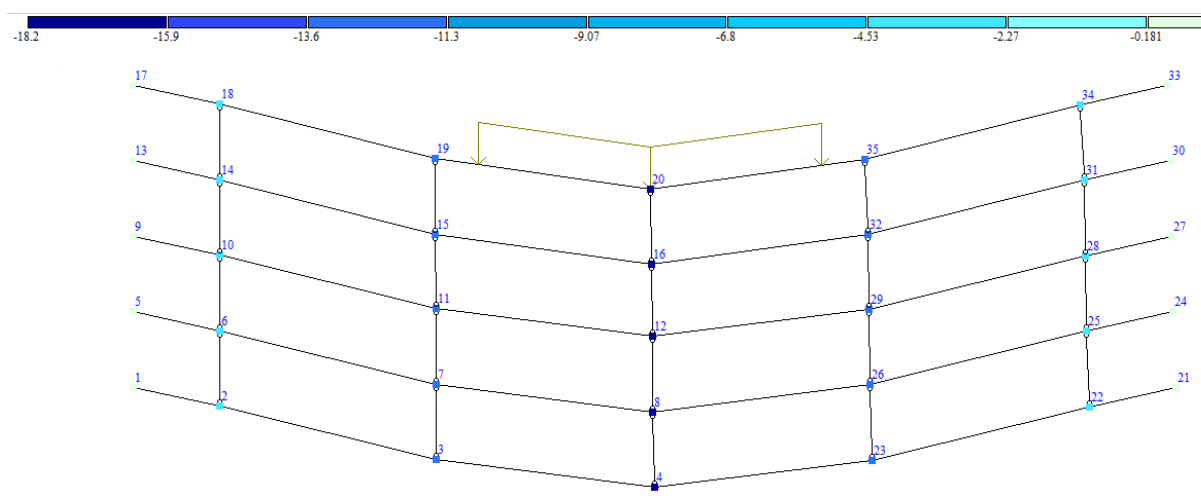

Fig. 4. Vertical displacements.

Due to considering of even spacing of the intermediate elements in the design model, the deflection of logs have decreased $(1.82 \mathrm{~cm}$ instead of $14 \mathrm{~cm}$ according to fig. 4$)$. In the central part of a log wall considerable internal forces emerge. By setting the intermediate elements it became possible to reallocate loads to another elements, and the forces decrease slightly (from -9.27 tons in the $18^{\text {th }}$ element to -1.68 tons in the $27^{\text {th }}$ one).

Table 3. The internal forces.

\begin{tabular}{|c|c|}
\hline Element № & N (tons) \\
\hline 27 & -1.68 \\
\hline 24 & -4.08 \\
\hline 19 & -6.52 \\
\hline 18 & -9.27 \\
\hline
\end{tabular}

\section{Conclusion}

During the study process, the following conclusions were made:

- The construction of the log wall was analyzed accurately. The received data contains information about wall geometrical proportions, such as length, diameters, the logs ideal position deviation (original curvature). The log ending junctions and contact zones of logs and its intermediate elements were also taken in consideration;

- Each log in a wooden wall was modelled by using FEM tools, optimal fixing conditions and bonds of elements were picked over and appropriate loadings was set on elements of a design scheme;

- Special methods of accounting the intermediate elements between logs were worked out in design scheme;

- As a calculation result, the information about stress-strain state were recieved

The study shows that it is necessary to compare the received data with results of field tests and standart values. The conclusions of this comparison will be used for proving (or rejecting) a need of construction reinforcement in the restoration of the Church of the Transfiguration process. Furthermore, it can be used for restoration of other similar wooden buildings. 


\section{References}

1. A. Onen, J. Jung, M. Dilek, D. Cheng, R. Broadwater, C. Scirbona, G. Cocks, S. Hamilton, X. Wang, EPCS 44, 495-505 (2016)

2. G. Qiao, T. Li, Y. Frank Chen, CBM 105, 435-447 (2016)

3. D. De León, C.A. González-Pérez, S. Díaz, D. Delgado, J.C. Arteaga, CRC, 22252229 (2012)

4. J. Seo, H. Park, ASCE, 716-726 (2015)

5. B. Serrano-Lanzarote, E. Fenollosa Forner, F. Arnau Paltor, IC 541, (2016)

6. U.K. Zolkafli, Z. Yahya, N. Zakaria, F.W. Akashah, A.S. Ali, SS 33, 309-321 (2015)

7. G.R. Petrozzi, F. Carbajal, C.J. Schexnayder, PPSDC 20, (2015)

8. J.L. Yuan, Y.D. Yan, D. Huang, C. Du, AMM 694, 95-101 (2014)

9. T. Tribulová, P. Kotlík, IJAH 9, 352-366 (2015)

10. C.R. Liñán, M.J. Morales Conde, P.R. De Hita, F.P. Gálvez, IJAH 9, 324-340 (2015)

11. E. Rodríguez-Mayorga, E. Yanes-Bustamante, A. Sáez-Pérez, IC 67, (2015)

12. B. Carlo, C. Pietro, D. Vincenzo, F. Nora, IAARC, 1-8 (2015)

13. I. Stefanou, M. Fragiadakis, I.N. Psycharis, CMAS 37, 61-82 (2015)

14. T. Aven, L.M. Pedersen, RESS 124, 165-170 (2014)

15. SP 64.13330.2011, Timber structures, (2011) 